\title{
Impact of Training on Expectation of Employee and Employer: A comparative study
}

\author{
Syed Muhammad Javed Iqbal, Agha Amad Nabi*, Saqib Muneer, Melati Ahmad Anuar \\ Universiti Teknologi Malaysia, Malaysia \\ *ammadagha@yahoo.com
}

\begin{abstract}
Organizations today spend millions of dollars on training to enhance the performance of their employees, which leads to formation of expectation on employers end as well as employees ends observing this phenomena ,this research was conducted to analyze the expectations of employee and employer and its impact on post training satisfaction, for that matter data was collected from 20 organization where training is provided ,sample size was 20 training / HR managers and per managers 5 employees, paired sample t test was applied to gauge the difference or similarity between the perception and expectation of employees and employer, after the analysis it was found that there is significant difference between the perception of employee and employers on the expected training outcomes and no similarity existed between the expectation of employee and employer which did not have positive effect on post training satisfaction.
\end{abstract}

Keyword: Employee's expectation, Employer's expectation, similar expectation, Post Training satisfaction

\section{Introduction}

The research has explored the relationship between the expectation of employee and employer after training has been conducted and the consequences if the expectation of the employee and employer are not met. The parties fulfilling their commitments put tension from time to time due to the hidden and implicit knowledge (incomplete contracts). Parties using hidden knowledge influence against each other. Furthermore uncertainties arising from changes in the market and innovations change parties of perception of expectation. This is due to tensions employers slog in fulfilling their commitments. On the other hand these uncertainties have to change and affect the employer behavior in the context of contractual relations (Top, 2013). Organizations today spend millions of dollars to train its employees to meet the objectives and employers believe training is strongly associated with superior performance; employers have several expectations from the employees after spending such a hefty amount on the employees. The link between performance and training is asserted by Holton (1996) gave a conceptual assessment model of training emphasized on employee performance. This model intends three initial results of training intervention: training, employee performance, and organizational results. These results are defined, respectively, as success of the training consequence desired in an HRD intervention, adjustment in employee performance as an effect of training being implemented on the vocation, and results at the organizational stages as a consequence of adjustment in employee performance.

At the same time employees are also subjected to rigorous training which results in formation of expectations from employee's side as well. In contemporary organizations one cannot deny the importance of training, so many writers time and again have asserted the importance of training. In this regard, traditional approaches to transfer of training tend to examine it as a horizontal link between training and performance. A detailed audit of the literature (Baldwin \& Ford, 1988) classified the factors impacting transfer of training into three categories: training inputs, encompassing trainee features, training plan, and organizational environment; (2) training outputs, consisting of education and retention; and (3) conditions of transfer, which concentrate on the generalization and maintenance of training. All three sets of training input qualities are perceived imposing on training and retention, which straight away affects generalization and maintenance. However, a valued purpose of training and expansion is to transforming performance (Swanson, 1995). Learning is of tiny worth to organizations unless it is transferred in numerous ways to performance (Holton, Bates, Seyler \& Carvalho, 1997). To study the similarity in Training outcomes. "Expectations of employee and employer and its impact on employees" 
Post Training Satisfaction. Kuchinke (1995) also asserted that training is a method, not organizational result; training is an internal behavior, although performance is broadly articulating a more external one. Therefore, training outputs ought to emphasize performance, not just learning. This is the employer's expectations from training that is why training has such a pivotal role in organizations. The employees have several expectations associated with training as well so full career expansion opportunities, such as career development Programs and training can be a motivator for personnel to enhance their dedication to organizational performance, The purpose of career expansion is to elevate employees' competence intellectual powers by delivering them that includes systematic programs so that it will enhance growth (Jacobs \& Washington, 2003) and the resulting developments also contributes positively to organizational performance. Employees' opportunities for advancement and development within organization are one of the factors for creating competitive work environments. After training has been provided to the employees if the expectations are fulfilled the employees plan to continue the career with in the same organization. Consequently, transformed subjective organizational performance can be looked ahead by personnel to perceive high chances of opportunities for career expansion and raises in their organizations (Kim, 2010).

\section{Figure 1: (Self Developed Research Model)}

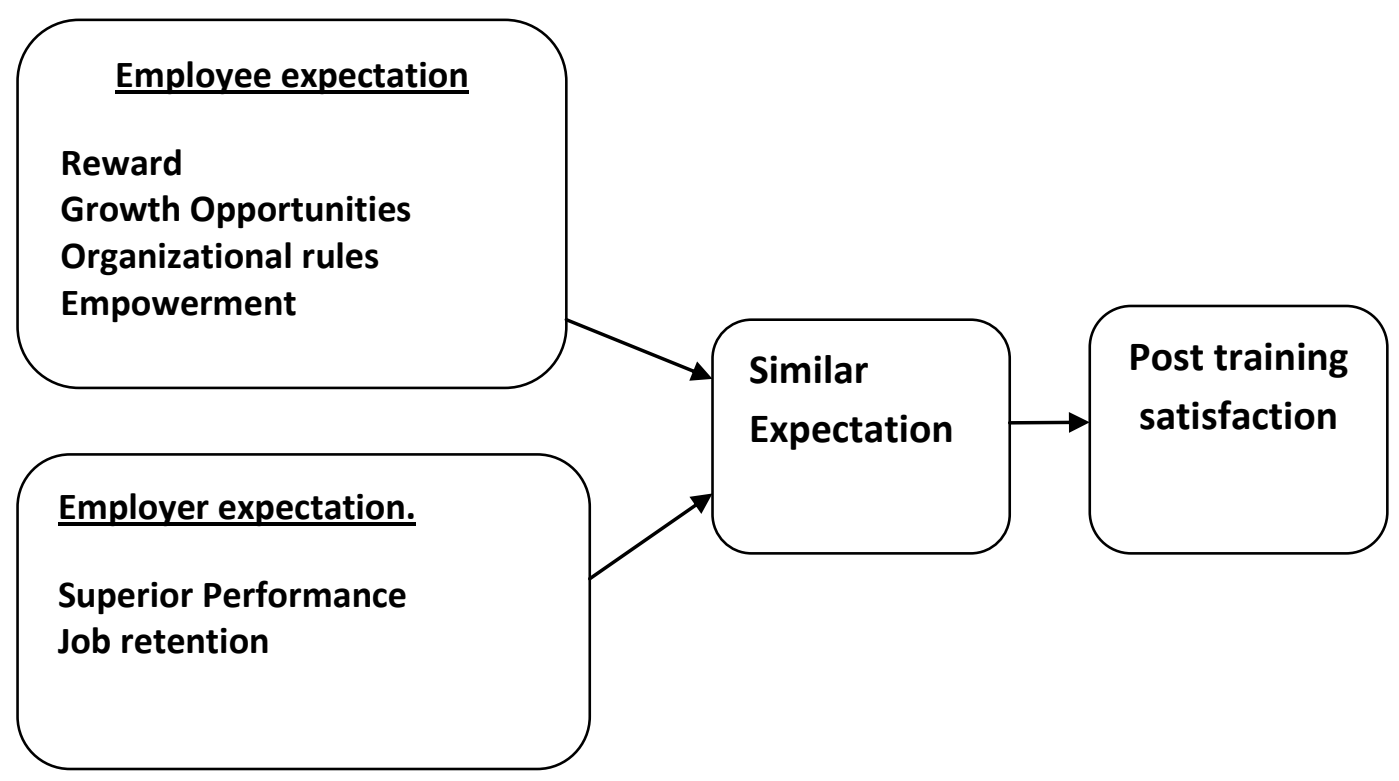

Independent Variable:

- Employee expectations.

- Employer's expectations

- Similar expectations

\section{Dependent Variable:}

- Post Training satisfaction.

Sub-variables of employee's expectation

- Rewards (kim,2010)

- Opportunities( Kim,2010)

- Organizational rules (Kim,2010)

- Empowerment (Kim,2010) 


\section{Sub variables of Employer's Expectation}

- organizational Performance (lowery,1998)

- Job Retention( King, 1974)

\section{Hypotheses}

$\mathrm{H}_{1}$ : There is no significant difference between the perception of employee and employer on the expected training outcomes.

$\mathrm{H}_{2}$ : The similarity between the employee and employer' has positive effect on post training satisfaction.

\section{Literature Review}

Today it's a known fact that an organization's competitive success is achieved through people. Many organizations invest much on training, expecting that training will transform the employees' performance and hence the firm's productivity (Yamnill \& McLean, 2001). There is powerful agreement that acquisition of information, abilities, behaviors, and mind-set is through training, training is of little worth if the new characteristics are not generalized to the job setting and are not sustained over time (Kozlowski \& Salas, 1997). Simply, training is ineffective if it will not be converted into better organizational practice (Yamnill \& McLean, 2001). According to Swanson (1995), for human resource development to become a vital organizational function performance is the key. Therefore, if organization accept as factual that training really makes a distinction in organizational and employees efficiency, organization should realize how to support and cascade of training in organizations. Managers should present constant response to let workers understand if their performance is in accordance to the established measures, founded on expectancy idea (Porter \& Lawler, 1968) and equity idea (Adam, 1963). Employees' opportunities for progress and growth within organizations also factor into composing competitive organization environments. Full career growth opportunities, such as career growth and training, were observed as a motivator for staff to boost their dedication to organizational performance (Kim, 2010). According to Lemire, Saba \& Gagnon's study on Quebec's civil service (1999), the career expansion plateau had adverse influence amidst on workers considering company's promise to the association, work environment and aim to stay in the organization.

The companies which reward to human resource expansion and the organizations that offered personnel more improvement and career expansion opportunities enable personnel to accomplish their tasks and duties efficiently. Such outcomes finally lead to optimistic influences on organizational performance (Li, 2000; Roback, 1989). The employees and employers expectations associated with training competitive work environments incorporate employees' advancement and career expansion possibilities with organizational performance (Swanson, 1995). After training has been provided an employee expect monetary awards will be provided by the merit remunerate system but this system may not be meaningful and convenient motivators for designing competitive professional environments and efficient performance (Nigro, Nigro \& Kellough, 2007). Furthermore, several researchers were worried regarding dysfunctional competition among workers affected by merit compensation because some employees expected intrinsic reward (Ingraham, 1993). It was observed that poorly managed compensation procedures after training had been provided can truly diminish contentment and motivation to perform for the person employed to execute the job (Kellough \& Selden, 1997). While composing a competitive environment the use of economic awards assisted to recruit experienced staff, payment for such workers can otherwise cost a disproportionate allowance of the organizational budget (Kim, 2010). According to Shields (2007), employees' anticipations, agreement and obligations either positively or adversely influenced work beliefs or behaviors, as well as bonds with other workers or supervisors created on the notion of "psychological contract."

In accordance to Ryall (2003) employees were occasionally found to exert subjective rationality based onto their expectations regarding the professional environment, incorporated their competitors' operation, which can otherwise possess a self-fulfilling influence onto employees' assessments of specified and organizational performance. It was found that organizational rules played a very pivotal role in building the expectation of employee and employer it was observed that after training has been provided to employee an employee expect there should be less rigidity in adherence of organization rules and norms of the organization 
simultaneously the employers regards such expectations to be irrelevant, In the opinion of Nigro et al. (2007), management was unable to know what employees value and those things must be taken in consideration by human resource management because staff has "needs that they want to satisfy, that they are able rationally to calculate expectancies and instrumentalities, and shall behave accordingly. Such organizational rules decline employees' competence. Therefore, associations with high performance are distinguished by having powerful organizational norms that are founded on comparable organizational heritage (Barney, 1986), because performance-based organizational directions stress a premium importance on excellence, they assist organizational missions (Kim, 2010).

Another significant component in advancing organizational work through comparable work environments is the span to which organizational norms are performance oriented. For a long time, the public companies has been identified as having rigid organizations, formalized job guidelines and responsibilities, inflexible pay schemes, and numerous constraints (Kurland \& Egan, 1999). Organizational culture is a combination of formal and informal norms that design employee beliefs, attitudes and conduct (Kerr \& Slocum, 1987). Organizational members are likely to put in more efforts if they believe that the promotions are based on performance and that high-performing staff are rewarded with higher payment (e.g., competition via comparison (Vickers, 1995). More importantly, the current study concentrates on several facets of human resource to create good organizational environment that an employee expects linked with organization reward (Newland, 1972; Nigro et al., 2007), opportunities for other tasks or promotions (Li, 2000; Nigro et al., 2007; Roback, 1989), organizational norms (Barney, 1986). This document gauges the relationship between worker perceptions of these practices and of organizational performance (Andrew, Boyne \& Walker 2006). Thriving implementation of pay-for-performance schemes needs that two critical connections be satisfied: first, that workers glimpse the connection between work and pay as clear and equitable, and second, that workers worth the pay itself. This connection emphasizes the significance of both employees' anticipations and insights and thriving for pay-for-performance systems (Kim, 2010).

\section{Methodology}

Method of Data Collection: Personal survey technique was employed on the above specified respondents. The researcher visited the organizations and carried out a questionnaire based survey to collect the information.

Sampling Technique: The quota sampling technique was applied to get the required set of information from respondents. The sample was selected from 20 organizations in which training is provided. The sample was conducted from 20 Training/HR Managers/Employers and their 5 subordinates/employee per manager. 20 managers from several companies and respective subordinates were interviewed on the basis of quota sampling. The decided sample quota was 20 employers and 5 employees per employer.

Sample Size: The sample size for the present study was 20 Training/HR Managers/Employers, and 100 subordinates or employee working within those organizations. Overall sample size for the current Study was 120 respondents.

Instrument of Data Collection: Questionnaire was the instrument for data collection. There was a separate questionnaire for the employee and employer both on same dimensions, Sec A measured similar expectation and sec B measured post training satisfaction in basis of 5 point likert scale.

\section{Table 1: Reliability Analysis}
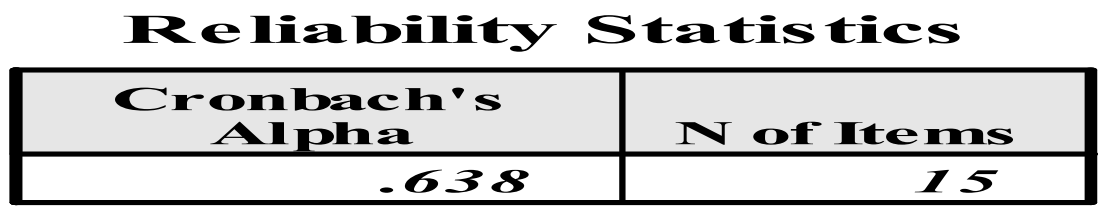

Over all reliability for the data set was observed 63.8\% according to Cronch's Alpha test statistics, which is adequate as per requirement. 
Content validity: The instrument developed for this Study has covered all the facets symptoms, phenomenon and behaviors relevant to this Study and the experts agree with it that the instrument through which the data has been collected is valid because procedure has produced the similar results over the period of time whenever statistical analysis has been performed.

Statistical Technique: Paired Sample T-Test was considered as an appropriate Statistical Technique for analyzing the responses collected from employers and Employees on the same dimensions. Furthermore, the hypotheses also suggested that it was the appropriate technique to know the best results, regarding the similarity or differences between responses of employers and employees on the post training expectations.

\section{Findings and Interpretations of the Results}

In reference to the hypotheses, the data collected via questionnaires was entered on SPSS 17.0, and then Paired Sample T-Test analysis was applied on the data to gauge the difference between the expectation of employee and employer after training had been provided. Table-1 (Paired Sample Statistics), showed that mean of employee perception i.e. 3.6620 (Aggregate Value of Employee perception) was not similar to the mean perception of employer i.e. 3.2450 (Aggregate Value of Employer perception). This suggested that the employee and employer perceptions for post training were different. Initially the sample size was 120 in total. There were 100 employees and 20 employers, causing an unequal sample size. Thus it was difficult to apply Paired Sample T-Test. So, the responses of every five employees related to the respective employer were averaged out to adjust unequal sample sizes of the both respondent groups. Standard Deviation of employee and employer perceptions was also found different as Shown in Table 2.

Table 2: Paired Sample Test

Paired Samples Statis tics

\begin{tabular}{|c|c|c|c|c|c|}
\hline & & Mean & $\mathbf{N}$ & Std. Deviation & $\begin{array}{c}\text { Std. Error } \\
\text { Mean }\end{array}$ \\
\hline \multirow{2}{*}{ Pair 1} & Perception_of_Employee & 3.6620 & 20 & .34580 & .07732 \\
\hline & Perception of Employer & 3.2450 & 20 & .43827 & .09800 \\
\hline
\end{tabular}

Paired Samples Test

\begin{tabular}{|c|c|c|c|c|c|c|c|c|c|}
\hline & \multicolumn{5}{|c|}{ Paired Differences } & \multirow[b]{3}{*}{$t$} & \multirow[b]{3}{*}{ df } & \multirow[b]{3}{*}{ Sig.(2-tailed) } \\
\hline & & \multirow[b]{2}{*}{ Mean } & \multirow[b]{2}{*}{ Std. Deviation } & \multirow{2}{*}{$\begin{array}{c}\text { Std. Error } \\
\text { Mean }\end{array}$} & \multicolumn{2}{|c|}{$\begin{array}{l}95 \% \text { Confidence Interval of the } \\
\text { Difference }\end{array}$} & & & \\
\hline & & & & & Lower & Upper & & & \\
\hline Pair 1 & $\begin{array}{l}\text { Perception_of Employee - } \\
\text { Perception of Employer }\end{array}$ & 41700 & .62192 & .13907 & .12593 & .70807 & 2.999 & 19 & .007 \\
\hline
\end{tabular}

\begin{tabular}{llll}
\hline Hypotheses & Significance level & t-statistics & Empirical Conclusion \\
\hline H1 & 0.007 & 2.99 & Rejected \\
PROPOSITION & Not Tested & Not Tested & Not Tested \\
\hline
\end{tabular}

After applying Paired Sample T-Test, a mean difference of 0.41700 was observed in the employee and employer responses regarding post training expectations, as shown in Table 2. Thus, it was concluded that there lies a significant difference between the perceptions of employee and employer on expected training outcome, because the significance value was found 0.007 which is less than 0.05 . So, the Null hypothesis 1 was rejected. In hypothesis 2 , since there is a mean difference of 0.41700 which was found significant because the P-Value was 0.007 so, on the basis of this result it was concluded that no similarity was found between employee and employer expectations and since there was no similarity it did not have any positive effect on post training satisfaction. So, the Null hypothesis $\mathrm{H} 2$ was not accepted. As hypothesis 2 was not tested so hypothesis 2 was then assumed as a proposition. 
Hypotheses Assessment Summary: After the application of Paired Sample T-Test the difference between perception of employee and employer was gauged. On the basis of P-Value which was found to be 0.007 Null hypothesis 1 was not accepted, (i.e. there is no significant difference between the perception of employee and employer on the expected training outcomes). In terms of proposition, since there was a significant difference observed between the perceptions of employee and employer on the basis of which it was concluded that no similarity exists between the employee and employer's expectation therefore it does not have any positive effect on post training satisfaction. Proposition was rejected (i.e. the similarity between the employee and employer' has positive effect on post training satisfaction).

\section{Conclusion}

It was concluded after the research results that there was great deal of difference between the expectation of employee and employer on the post training outcomes. As the second hypothesis further validated that there was no similarity in the perception and expectation of employee and employer so it does not have positive impact on post training satisfaction which created a discord in the expectation of employee and employer. Employees were found to expect greater rewards, good opportunities, and relaxation in organizational rules and greater empowerment after training has been provided, whereas, employers' expectations were very dissimilar and stressed more on superior performance.

Discussions: In today's contemporary organization there is a phenomenon of discord observed between the expectations of employee and employer. On the basis of which, there were consequences like employee turnover and dissatisfaction, and conversely satisfaction and retention as well. In order to analyze the expectations, a research was conducted to gauge these expectations. The research showed that there was a wide dissimilarity between the expectations and perceptions of employees and the respective employers. The employee expected greater rewards after training. Whereas employer expects improved performance and not giving much consideration to rewards, and consequently this does not have positive impact on post training satisfaction.

Implications and Recommendations: It is strongly recommended to employers to provide immediate feedback to the employees for the rectification of the performances there and then and to clear the expectation of employees. It was also observed that employer should cascade down the expectation to the employees so that employees do not feel that there are unrealistic objectives and expectations linked to the employees. A strategy of continuous feedback should be adopted by employee and employer both to eliminate the expectation discord. Training is a useless activity unless it is not transformed into the superior performance. So, an employer should make sure the employee is sent for the training to the field that is relevant to that particular employee. Additionally, it should be clear after the training what tasks an employee is expected to perform in a better way.

Limitations and Future Research: There was not much research work found related to the post training expectations of employee and employers. The present Study found that there are some difference between employee and employer's expectation and perception in connection to the post training performance and rewards systems. Besides this, the present Study lacks the content and factors that would eliminate the causes of the dissimilarities in the expected outcomes of training and the consequent performances. However, the present study had opened up the ways to explore about these factors and causes that would cause difference between employee and employers post training expectation. Future research work must focus to minimize this difference between employee and employers expectations to enhance post training outcomes.

\section{References}

Adams, J. S. (1963). Toward an understanding of inequity. Journal of Abnormal and Social Psychology, 67, 422463.

Andrews, R., Boyne, G. A. \& Walker, R. M. (2006). Subjective and Objective Measures of Organizational Performance: An Empirical Exploration. In Public Service Performance: Perspectives on 
Measurement and Management, edited by George A. Boyne, Kenneth J. Meier, Laurence J. O’Toole Jr., and Richard M. Walker, 14-34. New York: Cambridge University Press

Baldwin, T. T. \& Ford, J. K. (1988). Transfer of training: A review and directions for future Research. Personnel Psychology, 41(2), 63-105.

Barney, J. R. (1986). Organization Culture: Can It Be a Source of Sustained Competitive Advantage? Academy of Management Review, 11(3), 656-65.

Holton, E. F. (1996). The flawed four-level evaluation model. Human Resource Development Quarterly, 7(1), 525.

Holton, E. F., Bates, R. A., Seyler, D. L. \& Carvalho, M. B. (1997). Toward construct validation of a transfer climate instrument. Human Resource Development Quarterly, 8(2), 95-113.

Ingraham, P. W. (1993). Pay for Performance in the States. American Review of Public Administration, 23(3), 189-200.

Jacobs, R. L. \& Washington, C. (2003). Employee Development and Organizational Performance: A Review of Literature and Directions for Future, Research. International of Human Resource Development, 6(3), 343-54

Kellough, J. E. \& Selden, S. C. (1997). Pay-for-Performance Systems in State Government: Perceptions of State Agency Personnel Managers. Review of Public Personnel Administration, 17(1), 5-21.

Kerr, J. \& Slocum-Jr., J. W. (1987). Managing Corporate Culture through Reward Systems. Academy of Management Executive, 1(2), 99-107

Kim, J. (2010). Strategic Human resource practices: Introducing alternatives for organization performance improvement in the public sector. Academy of Management Executive, 7(2), 38-49

King, A. S. (1974). Expectation Effects in Organizational Change. Administrative Science Quarterly, 2, 221-230.

Kozlowski, S. W. J. \& Salas, E. (1997). A multilevel organizational systems approach for the implementation and transfer of training. In J. Kevin Ford (Ed.), Improving training effectiveness in work organizations (pp. 247-287).

Kuchinke, K. P. (1995). Managing learning for performance. Human Resource Development Quarterly, 6(3), 307-316.

Kurland, N. B. \& Egan, T. D. (1999). Public v. Private Perceptions of Formalization, Outcomes, and Justice. Journal of Public Administration Research and Theory, 9(3), 437-58.

Lemire, L., Saba, T. \& Gagnon, Y. C. (1999). Managing Career Plateauing in the Quebec Public Sector. Public Personnel Management, 28(3), 375-92.

Li, L. X. (2000). An Analysis of Sources of Competitiveness and Performance of Chinese Manufacturers. International Journal of Operations and Production Management, 20(3), 299-315.

Lowery, D. (1998), Consumer Sovereignty and Quasi-Market Failure. Journal of Public Administration Research and Theory, 8(2), 137-72.

Newland C. A. (1972). Personnel Concerns in Government Productivity Improvement. Public Administration Review, 32(6), 807-15

Nigro, L. G., Nigro, F. A. \& Kellough, J. E. (2007). The New Public Personnel Administration. 6th ed. Belmont, CA: Thomson/Wadsworth.

Porter, L. W. \& Lawler, E. E. (1968). Management attitude and performance. Florence, KY: Dorsey Press.

Roback, T. H. (1989). Personnel Research Perspectives on Human Resource Management and Development. Public Personnel Management, 18(2), 138-62.

Ryall, M. D. (2003). Subjective Rationality, Self-Confirming Equilibrium, and Corporate Strategy. Management Science, 49(7), 936-49.

Shields, J. (2007). Managing Employee Performance and Reward: Concept, Practices, Strategies. New York: Cambridge University Press.

Swanson, R. A. (1995). Human resource development: Performance is the key. Human Resource Development Quarterly, 6(2), 207-213.

Vickers, J. (1995). Concepts of Competition. Oxford Economic Papers, 47(1), 1-23.

Yamnill, S. \& McLean, G. N. (2001). Theories Supporting Transfer of Training. human resource development quarterly, 12(2).

Top, L. (2013). Social and Behavioral Sciences, 230 - 239 